\title{
PD Power-Level Control Design for MHTGRs
}

\author{
Zhe Dong \\ Institute of Nuclear and New Energy Technology, Tsinghua University, Beijing, China \\ Email: dongzhe@mail.tsinghua.edu.cn
}

Received December 2013

\begin{abstract}
Due to its inherent safety feature, the modular high temperature gas-cooled reactor (MHTGR) has been seen as one of the best candidates in building next generation nuclear plants (NGNPs). Since the MHTGR dynamics has high nonlinearity, it is necessary to develop nonlinear power-level controller which is not only beneficial to the safe, stable, efficient and autonomous operation of the MHTGR but also easy to be implemented practically. In this paper, based on the concept of shiftedectropy and the physically-based control design approach, it is proved theoretically that the simple proportional-differential (PD) output-feedback power-level control can provide globally asymptotic closed-loop stability. Numerical simulation results verify the theoretical results and show the influence of the controller parameters to the dynamic response.
\end{abstract}

\section{Keywords}

Modular High Temperature Gas-Cooled Reactor (MHTGR); Power-Level Control; Closed-Loop Stability

\section{Introduction}

Due to its inherent safety performance, the modular high temperature gas-cooled reactor (MHTGR) has been seen as one of the best candidates for building next generation nuclear plants. The MHTGR uses helium as coolant and graphite as moderator and structural material, and its inherent safety is given by the low power density, strong negative temperature feedback effect and slim reactor shape [1]. China began to study the MHTGR at the end of 1970s, and a 10 MWth pebble-bed high temperature gas-cooled test reactor HTR-10 designed by institute of nuclear and new energy technology (INET) of Tsinghua University achieved its criticality in December 2000 and full power in January 2003 [2]. Then, six safety demonstration tests were done on HTR-10, which manifested its inherent safety and self-stabilizing features [3]. Based on the experience of the HTR-10 project, a high temperature gas-cooled reactor pebble-bed module (HTR-PM) project was then proposed [4]. As shown in Figure 1, the HTR-PM plant consists of two one-zone MHTGRs with combined thermal power of $2 \times 250 \mathrm{MW}_{\mathrm{th}}$, and has the structure of two nuclear steam supplying systems (NSSSs) driving one steam turbine [4]. Here, the NSSS is composed of an MHTGR, a helical coiled once-through steam generator (OTSG) and some connecting pipes.

Since a MHTGR is essentially a nonlinear dynamical system, it is necessary to develop nonlinear power-level control laws of the MHTGR for safe, stable and efficient operation. Actually, nonlinear power-level control design is a hot field in nuclear engineering, and there have been some promising nonlinear reactor control design methods. Shtessel gave a nonlinear power-level regulator based on sliding mode control and observation tech- 
niques for space reactor TOPAZ II [5]. Dong designed a dynamic output feedback dissipation power-level control for the pressurized water reactors (PWRs) [6] by the use of the backstepping technique [7] and dissipation-based high gain filter (DHGF) [8,9]. Etchepareborda and Eliasi proposed the nonlinear MPC (NMPC) method for PWR power-level control design [10-12]. However, the forms of the above nonlinear power-level control laws are too complicated to be implemented practically. Control design by fully using the good natural system dynamics, i.e. the physically-based control design method can lead to simple and effective controllers, and is a promising trend of advanced control theory [13-15]. Very recently, based on the physically-based design approach, Dong proposed a nonlinear dynamic output-feedback power-level control for the PWRs [16], and also proved theoretically that the simple proportional-differential (PD) power-level control could guarantee globally asymptotic closed-loop stability for the PWRs [17].

Since the dynamic features of the MHTGR is different from that of the PWR, the power-level control designed for the PWR cannot directly applied to the MHTGR. It is necessary to develop nonlinear power-level controller for the MHTGRs. Dong designed a nonlinear state-feedback power-level control strategy to the MHTGR based on the technique of iterative damping assignment (IDA) [18]. Although this IDA-based control can provide globally asymptotic closed-loop stability, its mathematical form is too complex to be implemented practically. Based upon the physically-based control design approach, Dong also gave a nonlinear dynamic output feedback power-level controller for the MHTGR [19]. However, this control is still complicated in its form. Therefore, it is necessary to design simple power-level control laws for the MHTGR with strong load following capability.

In this paper, based on the concept of shifted-ectropy and physically-based control design method, it is proved theoretically that the static output-feedback control with simple PD structure can globally asymptotically stabilize the MHTGR. Numerical simulation results not only verify the theoretical results but also illustrate the relationship between performance and controller parameters.

\section{Problem Formulation}

\subsection{Nonlinear State-Space Model}

As shown in Figure 1, the MHTGR and OTSG of the NSSS is arranged side by side, and is connected to each other by a horizontal coaxial gas duct. The cold helium enters the main blower mounted on top of the OTSG, and is pressurized before flowing into the cold gas duct. It enters the channels inside the reflector of the core, and then passes through the pebble-bed from top to bottom where it is heated to a high temperature. The hot helium leaves the hot gas chamber at the bottom reflector, and flows into the primary side of the OTSG through the hot gas duct. The primary loop can be nodalized as the elements given in Figure 2 .

By adopting the point kinetics with one equivalent delayed neutron group and with the temperature reactivity feedback effect of the pebble-bed/reflector community, the dynamical model for control design can be written as

$$
\left\{\begin{array}{l}
\dot{n}_{\mathrm{r}}=\frac{\rho_{\mathrm{r}}-\beta}{\Lambda} n_{\mathrm{r}}+\frac{\beta}{\Lambda} c_{\mathrm{r}}+\frac{\alpha_{\mathrm{R}}}{\Lambda} n_{\mathrm{r}}\left(T_{\mathrm{R}}-T_{\mathrm{R}, \mathrm{m}}\right), \\
\dot{c}_{\mathrm{r}}=\lambda\left(n_{\mathrm{r}}-c_{\mathrm{r}}\right), \\
\dot{T}_{\mathrm{R}}=-\frac{\Omega_{\mathrm{p}}}{\mu_{\mathrm{R}}}\left(T_{\mathrm{R}}-T_{\mathrm{H}}\right)+\frac{P_{0}}{\mu_{\mathrm{R}}} n_{\mathrm{r}}, \\
\dot{T}_{\mathrm{H}}=\frac{\Omega_{\mathrm{p}}}{\mu_{\mathrm{H}}}\left(T_{\mathrm{R}}-T_{\mathrm{H}}\right)-\frac{\Omega_{\mathrm{s}}}{\mu_{\mathrm{H}}}\left(T_{\mathrm{H}}-T_{\mathrm{S}}\right), \\
\dot{\rho}_{\mathrm{r}}=G_{\mathrm{r}} z_{\mathrm{r}},
\end{array}\right.
$$

where $n_{\mathrm{r}}$ is the relative neutron power, $c_{\mathrm{r}}$ is the relative concentration of delayed neutron precursor, $\beta$ is the fraction of delayed fission neutrons, $\Lambda$ is the effective prompt neutron life time, $\rho_{\mathrm{r}}$ is the reactivity provided by the control rods, $\lambda$ is the effective radioactive decay constant of the precursor, $T_{\mathrm{R}}$ and $\alpha_{\mathrm{R}}$ is the temperature and reactivity feedback coefficient of the community constituted by both the pebble-bed and reflector respectively, $T_{\mathrm{R}, \mathrm{m}}$ is the initial equilibrium value of $T_{\mathrm{R}}, P_{0}$ is the rated reactor thermal power, $T_{\mathrm{H}}$ is the average helium temperature of the primary side, $T_{\mathrm{S}}$ is the average coolant temperature of the secondary side of the OTSG, $\Omega_{\mathrm{p}}$ is the heat transfer coefficient between the helium and pebble- bed/reflector community, $\Omega_{\mathrm{s}}$ is the heat transfer coefficient 


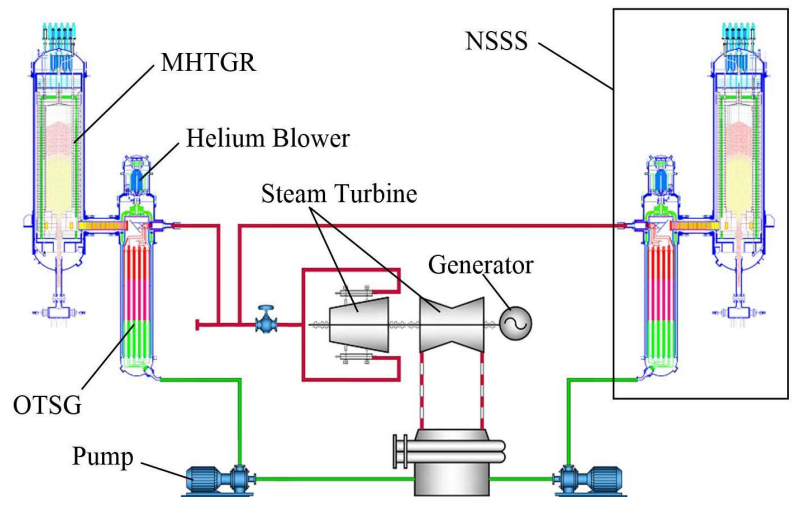

Figure 1. Composition of the HTR-PM plant.

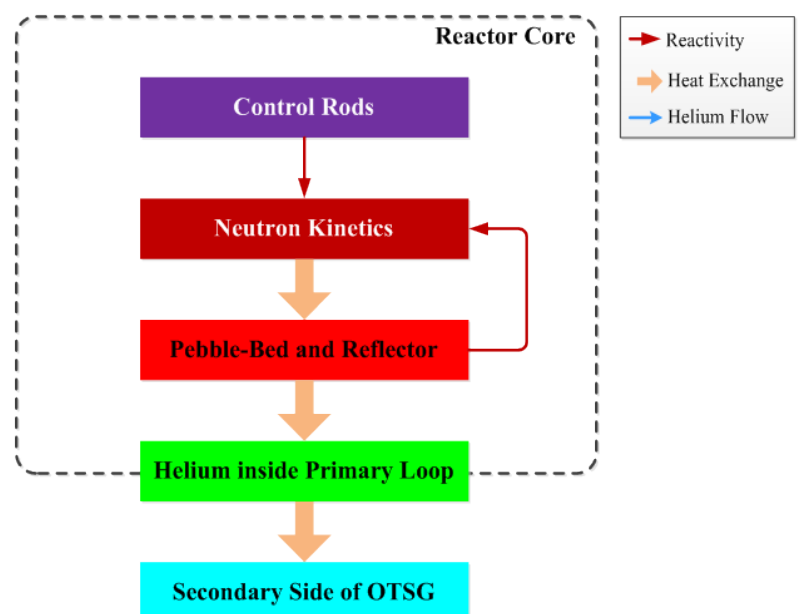

Figure 2. Nodalization of the primary loop.

between the two sides of OTSG, $\mu_{\mathrm{R}}$ and $\mu_{\mathrm{H}}$ is respectively the total heat capacities of the pebble-bed/reflector community and helium inside the primary loop, $G_{\mathrm{r}}$ is the total differential reactivity worth of the control rod, and $z_{\mathrm{r}}$ is the rod speed signal. Here, note that $\alpha_{\mathrm{R}}$ is guaranteed to be negative by physical design of the MHTGR.

Define the deviations of the actual values of $n_{\mathrm{r}}, c_{\mathrm{r}}, T_{\mathrm{R}}, T_{\mathrm{H}}, T_{\mathrm{S}}$ and $\rho_{\mathrm{r}}$ from their equilibrium values, i.e. $n_{\mathrm{r} 0}, c_{\mathrm{r} 0}$, $T_{\mathrm{R} 0}, T_{\mathrm{H} 0}$ and $\rho_{\mathrm{r} 0}$ as $\delta n_{\mathrm{r}}=n_{\mathrm{r}}-n_{\mathrm{r} 0}, \delta c_{\mathrm{r}}=c_{\mathrm{r}}-c_{\mathrm{r} 0}, \delta T_{\mathrm{R}}=T_{\mathrm{R}}-T_{\mathrm{R} 0}, \delta T_{\mathrm{H}}=T_{\mathrm{H}}-T_{\mathrm{H} 0}, \delta T_{\mathrm{S}}=T_{\mathrm{S}}-T_{\mathrm{S} 0}$, and $\delta \rho_{\mathrm{r}}=\rho_{\mathrm{r}}-\rho_{\mathrm{r} 0}$. Here, $\delta T_{\mathrm{S}}$ reflects the influence of the secondary to primary loop, and can be well suppressed by adjusting the feedwater flow-rate of the OTSG. Therefore, in this paper, the influence of $\delta T_{\mathrm{S}}$ is omitted. Let

$$
\begin{aligned}
\boldsymbol{x}=\left[\begin{array}{llll}
x_{1} & x_{2} & x_{3} & x_{4}
\end{array}\right]^{\mathrm{T}}=\left[\begin{array}{llll}
\delta n_{\mathrm{r}} & \delta c_{\mathrm{r}} & \delta T_{\mathrm{R}} & \delta T_{\mathrm{H}}
\end{array}\right]^{\mathrm{T}}, \\
\xi=\delta \rho_{\mathrm{r}},
\end{aligned}
$$

and

$$
\boldsymbol{u}=\boldsymbol{G}_{\mathbf{r}} z_{\mathbf{r}} .
$$

Here, $\boldsymbol{x}$ is the reactor state-vector of the MHTGR. Then, the nonlinear state-space model for control design can be written as

$$
\left\{\begin{array}{l}
\dot{\boldsymbol{x}}=\boldsymbol{f}(\boldsymbol{x})+\boldsymbol{g}(\boldsymbol{x}) \xi, \\
\dot{\xi}=\boldsymbol{u}, \\
\boldsymbol{y}=\boldsymbol{h}(\boldsymbol{x}),
\end{array}\right.
$$

where 


$$
\boldsymbol{f}(\boldsymbol{x})=\left[\begin{array}{c}
-\frac{\beta}{\Lambda}\left(x_{1}-x_{2}\right)+\frac{\alpha_{\mathrm{R}}}{\Lambda}\left(n_{\mathrm{r} 0}+x_{1}\right) x_{3} \\
\lambda\left(x_{1}-x_{2}\right) \\
\frac{P_{0}}{\mu_{\mathrm{R}}} x_{1}-\frac{\Omega_{\mathrm{p}}}{\mu_{\mathrm{R}}}\left(x_{3}-x_{4}\right) \\
\frac{\Omega_{\mathrm{p}}}{\mu_{\mathrm{H}}}\left(x_{3}-x_{4}\right)-\frac{\Omega_{\mathrm{s}}}{\mu_{\mathrm{H}}} x_{4}
\end{array}\right],
$$

and

$$
\boldsymbol{h}(\boldsymbol{x})=\left[\begin{array}{ll}
x_{1} & x_{4}
\end{array}\right]^{\mathrm{T}} .
$$

\subsection{Theoretic Problem}

Based on the above modeling, the theoretic problem to be solved in this paper is summarized as follows.

Problem 1. How to design an output-feedback PD control law of nonlinear system (5) taking the form as

$$
u=u(\boldsymbol{y}, \dot{\boldsymbol{y}}),
$$

so that $\boldsymbol{x} \rightarrow \boldsymbol{O}$ as $t \rightarrow \infty$ ?

\section{PD Power-Level Control Design}

Following Theorem 1, i.e. the main result of this paper, shows that simple output-feedback PD power-level control law can guarantee asymptotic closed-loop stability of reactor state-variables.

Theorem 1. There exists a PD power-level control law of nonlinear system (5) that provides globally asymptotic closed-loop stability for the reactor state of the MHTGR, i.e. $\boldsymbol{x} \rightarrow \boldsymbol{O}$ as $t \rightarrow \infty$.

Proof: Based upon the idea of backstepping, a virtual control input $\xi_{\mathrm{r}}$ is firstly designed for subsystem

$$
\left\{\begin{array}{l}
\dot{\boldsymbol{x}}=\boldsymbol{f}(\boldsymbol{x})+\boldsymbol{g}(\boldsymbol{x}) \xi_{\mathrm{r}}, \\
\boldsymbol{y}=\boldsymbol{h}(\boldsymbol{x}) .
\end{array}\right.
$$

From [17], the shifted-ectropy of neutron kinetics is

$$
\zeta_{\mathrm{N}}\left(x_{1}, x_{2}\right)=n_{\mathrm{r} 0}\left\{\Lambda\left[\left(1+\frac{x_{1}}{n_{\mathrm{r} 0}}\right)-\ln \left(1+\frac{x_{1}}{n_{\mathrm{r} 0}}\right)\right]+\frac{\beta}{\lambda}\left[\left(1+\frac{x_{2}}{n_{\mathrm{r} 0}}\right)-\ln \left(1+\frac{x_{2}}{n_{\mathrm{r} 0}}\right)\right]\right\} .
$$

Based on (11), let the Lyapunov function for the neutron kinetics be

$$
V_{\mathrm{N}}\left(x_{1}, x_{2}\right)=\zeta_{\mathrm{N}}\left(x_{1}, x_{2}\right)+\frac{k_{\mathrm{I}}}{2}\left[\int_{0}^{t} x_{1}(s) \mathrm{d} s\right]^{2} .
$$

Here, the objective of adding the second term of $V_{\mathrm{N}}$ is to minimize the steady error of $n_{\mathrm{r}}$ by feedback control. Then, differentiate $V_{\mathrm{N}}$ along the trajectory given by neutron kinetics, and we have

$$
\dot{V}_{\mathrm{N}}\left(x_{1}, x_{2}\right)=-\frac{\beta\left(x_{1}-x_{2}\right)^{2}}{\left(n_{\mathrm{r} 0}+x_{1}\right)\left(n_{\mathrm{r} 0}+x_{2}\right)}+x_{1}\left[\xi_{\mathrm{r}}+\alpha_{\mathrm{R}} x_{3}+k_{\mathrm{I}} \int_{0}^{t} x_{1}(s) \mathrm{d} s\right] .
$$

Moreover, it is clear that the shifted-ectropy of reactor thermal-hydraulics can be written as

$$
\zeta_{\mathrm{T}}\left(x_{3}, x_{4}\right)=\frac{1}{2}\left(\mu_{\mathrm{R}} x_{3}^{2}+\mu_{\mathrm{H}} x_{4}^{2}\right) .
$$

Then, based on (14), let the Lyapunov function of reactor thermal-hydraulics be 


$$
V_{\mathrm{T}}\left(x_{3}, x_{4}\right)=(1-\gamma) \zeta_{\mathrm{T}}\left(x_{3}, x_{4}\right)+\gamma \varsigma_{\mathrm{T}}\left(x_{3}, x_{4}\right),
$$

where $\gamma$ is a positive given constant satisfying $0<\gamma<1$, and

$$
\varsigma_{\mathrm{T}}=\frac{1}{2 \mu_{\mathrm{R}}}\left[\mu_{\mathrm{R}} x_{3}+\mu_{\mathrm{H}} x_{4}+\Omega_{\mathrm{S}} \int_{0}^{t} x_{4}(s) \mathrm{d} s\right]^{2}
$$

denotes the energy variation of the thermal-hydraulic loops. Differentiate (15) along the trajectory given by the reactor thermal-hydraulics, and we have

$$
\begin{aligned}
\dot{V}_{\mathrm{T}}= & P_{0} x_{1} x_{3}+\gamma P_{0} x_{1}\left[\frac{\mu_{\mathrm{H}}}{\mu_{\mathrm{R}}} x_{4}+\frac{\Omega_{\mathrm{s}}}{\mu_{\mathrm{R}}} \int_{0}^{t} x_{4}(s) \mathrm{d} s\right]-(1-\gamma)(1-\eta)\left[\Omega_{\mathrm{p}}\left(x_{3}-x_{4}\right)^{2}+\Omega_{\mathrm{s}} x_{4}^{2}\right] \\
& -(1-\gamma) \eta\left[\left(\Omega_{\mathrm{p}}+\Omega_{\mathrm{s}}\right)\left(x_{4}-\frac{\Omega_{\mathrm{p}}}{\Omega_{\mathrm{p}}+\Omega_{\mathrm{s}}} x_{3}\right)^{2}+\frac{\Omega_{\mathrm{p}} \Omega_{\mathrm{s}}}{\Omega_{\mathrm{p}}+\Omega_{\mathrm{s}}} x_{3}^{2}\right],
\end{aligned}
$$

where $\eta$ is given positive constant satisfying $0<\eta<1$.

Choose the Lyapunov function for subsystem (10) as

$$
V_{1}(x)=V_{\mathrm{N}}\left(x_{1}, x_{2}\right)+\frac{q_{\mathrm{R}}}{P_{0}} V_{\mathrm{T}}\left(x_{3}, x_{4}\right),
$$

where $q_{\mathrm{R}}$ is a given positive constant, $V_{\mathrm{N}}$ and $V_{\mathrm{T}}$ is given by (12) and (15) respectively. Differentiate (18) along the trajectory given by subsystem dynamics (10), and we can derive that

$$
\begin{aligned}
\dot{V}_{1}= & -\frac{\beta\left(x_{1}-x_{2}\right)^{2}}{\left(n_{\mathrm{r} 0}+x_{1}\right)\left(n_{\mathrm{r} 0}+x_{2}\right)}-(1-\gamma)(1-\eta) \frac{q_{\mathrm{R}}}{P_{0}}\left[\Omega_{\mathrm{p}}\left(x_{3}-x_{4}\right)^{2}+\Omega_{\mathrm{s}} x_{4}^{2}\right] \\
& -(1-\gamma) \eta q_{\mathrm{R}} \frac{\Omega_{\mathrm{p}}+\Omega_{\mathrm{s}}}{P_{0}}\left(x_{4}-\frac{\Omega_{\mathrm{p}}}{\Omega_{\mathrm{p}}+\Omega_{\mathrm{s}}} x_{3}\right)^{2}-\frac{q_{\mathrm{R}}}{2 \Sigma_{\mathrm{R}}}\left\{x_{3}^{2}+\left[x_{3}-\Sigma_{\mathrm{R}}\left(1+\frac{\alpha_{\mathrm{R}}}{q_{\mathrm{R}}}\right) x_{1}\right]^{2}\right\} \\
& +x_{1}\left\{\xi_{\mathrm{r}}+\frac{q_{\mathrm{R}} \Sigma_{\mathrm{R}}}{2 P}\left(1+\frac{\alpha_{\mathrm{R}}}{q_{\mathrm{R}}}\right)^{2} x_{1}+k_{\mathrm{I}} \int_{0}^{t} x_{1}(s) \mathrm{d} s+\gamma q_{\mathrm{R}}\left[\frac{\mu_{\mathrm{H}}}{\mu_{\mathrm{R}}} x_{4}+\frac{\Omega_{\mathrm{s}}}{\mu_{\mathrm{R}}} \int_{0}^{t} x_{4}(s) \mathrm{d} s\right]\right\}
\end{aligned}
$$

where

$$
\Sigma_{\mathrm{R}}=\frac{\left(\Omega_{\mathrm{p}}+\Omega_{\mathrm{s}}\right) P_{0}}{(1-\gamma) \eta \Omega_{\mathrm{p}} \Omega_{\mathrm{s}}} .
$$

From equation (19), if we design virtual control $\xi_{\mathrm{r}}$ as

$$
\xi_{\mathrm{r}}=-k_{\mathrm{ND}} x_{1}-k_{\mathrm{I}} \int_{0}^{t} x_{1}(s) \mathrm{d} s-\gamma q_{\mathrm{R}}\left[\frac{\mu_{\mathrm{H}}}{\mu_{\mathrm{R}}} x_{4}+\frac{\Omega_{\mathrm{s}}}{\mu_{\mathrm{R}}} \int_{0}^{t} x_{4}(s) \mathrm{d} s\right],
$$

where

$$
k_{\mathrm{ND}}>\frac{q_{\mathrm{R}}(1-\gamma) \eta \Omega_{\mathrm{p}} \Omega_{\mathrm{s}}}{2 P_{0}\left(\Omega_{\mathrm{p}}+\Omega_{\mathrm{s}}\right)}\left(1+\frac{\alpha_{\mathrm{R}}}{q_{\mathrm{R}}}\right)^{2},
$$

then the closed-loop subsystem constituted by (10) and (21) is globally asymptotically stable.

Now, we design the control law for entire system (5). Choose the Lyapunov function of the entire system as

$$
V_{2}\left(x, e_{\xi}\right)=V_{1}(x)+\frac{e_{\xi}^{2}}{2 k_{\xi}},
$$

where $k_{\xi}$ is a given positive constant, and

$$
e_{\xi}=\xi-\xi_{\mathrm{r}},
$$


Differentiate (23) along the trajectory given by entire system dynamics (5), and we have

$$
\begin{aligned}
\dot{V}_{2}= & -\frac{\beta\left(x_{1}-x_{2}\right)^{2}}{\left(n_{\mathrm{r} 0}+x_{1}\right)\left(n_{\mathrm{r} 0}+x_{2}\right)}-(1-\gamma)(1-\eta) \frac{q_{\mathrm{R}}}{P_{0}}\left[\Omega_{\mathrm{p}}\left(x_{3}-x_{4}\right)^{2}+\Omega_{\mathrm{s}} x_{4}^{2}\right] \\
& -(1-\gamma) \eta q_{\mathrm{R}} \frac{\Omega_{\mathrm{p}}+\Omega_{\mathrm{s}}}{P_{0}}\left(x_{4}-\frac{\Omega_{\mathrm{p}}}{\Omega_{\mathrm{p}}+\Omega_{\mathrm{s}}} x_{3}\right)^{2}-\frac{q_{\mathrm{R}}}{2 \Sigma_{\mathrm{R}}}\left\{x_{3}^{2}+\left[x_{3}-\Sigma_{\mathrm{R}}\left(1+\frac{\alpha_{\mathrm{R}}}{q_{\mathrm{R}}}\right) x_{1}\right]^{2}\right\} \\
& -\tilde{k}_{\mathrm{ND}} x_{1}^{2}+x_{1} e_{\xi}+\frac{1}{k_{\xi}} e_{\xi}\left(u-\dot{\xi}_{\mathrm{r}}\right),
\end{aligned}
$$

where

$$
\tilde{k}_{\mathrm{ND}}=k_{\mathrm{ND}}-\frac{q_{\mathrm{R}}(1-\gamma) \eta \Omega_{\mathrm{p}} \Omega_{\mathrm{s}}}{2 P_{0}\left(\Omega_{\mathrm{p}}+\Omega_{\mathrm{s}}\right)}\left(1+\frac{\alpha_{\mathrm{R}}}{q_{\mathrm{R}}}\right)^{2} .
$$

From (25), if we choose feedback control $u$ as

$$
u=-k_{\xi} X_{1}+\dot{\xi}_{\mathrm{r}}=-\left(k_{\mathrm{NP}} X_{1}+k_{\mathrm{ND}} \dot{x}_{1}+k_{\mathrm{TP}} X_{4}+k_{\mathrm{TD}} \dot{x}_{4}\right),
$$

where

$$
\begin{array}{r}
k_{\mathrm{NP}}=k_{\xi}+k_{\mathrm{I}}, \\
k_{\mathrm{TP}}=\gamma q_{\mathrm{R}} \frac{\Omega_{\mathrm{s}}}{\mu_{\mathrm{R}}},
\end{array}
$$

and

$$
k_{\mathrm{TD}}=\gamma q_{\mathrm{R}} \frac{\mu_{\mathrm{H}}}{\mu_{\mathrm{R}}},
$$

then we have

$$
\begin{aligned}
\dot{V}_{2}= & -\tilde{k}_{\mathrm{ND}} x_{1}^{2}-\frac{\beta\left(x_{1}-x_{2}\right)^{2}}{\left(n_{\mathrm{r} 0}+x_{1}\right)\left(n_{\mathrm{r} 0}+x_{2}\right)}-(1-\gamma)(1-\eta) \frac{q_{\mathrm{R}}}{P_{0}}\left[\Omega_{\mathrm{p}}\left(x_{3}-x_{4}\right)^{2}+\Omega_{\mathrm{s}} x_{4}^{2}\right] \\
& -(1-\gamma) \eta q_{\mathrm{R}} \frac{\Omega_{\mathrm{p}}+\Omega_{\mathrm{s}}}{P_{0}}\left(x_{4}-\frac{\Omega_{\mathrm{p}}}{\Omega_{\mathrm{p}}+\Omega_{\mathrm{s}}} x_{3}\right)^{2}-\frac{q_{\mathrm{R}}}{2 \Sigma_{\mathrm{R}}}\left\{x_{3}^{2}+\left[x_{3}-\Sigma_{\mathrm{R}}\left(1+\frac{\alpha_{\mathrm{R}}}{q_{\mathrm{R}}}\right) x_{1}\right]^{2}\right\} .
\end{aligned}
$$

Based on equation (31), it is clear that there always exists a PD power-level controller (27) so that reactor state $\boldsymbol{x}$ of MHTGR dynamics (5) are globally asymptotically stable. This completes the proof of this theorem.

Remark 1. From equation (12) and (28), the steady error of relative nuclear power can be suppressed by enlarging the proportional feedback gain $k_{\mathrm{NP}}$ corresponding to $\delta n_{\mathrm{r}}$. Also from (18), the dynamic performance of the thermal-hydraulic loop can be strengthened through enlarging $q_{\mathrm{R}}$, which certainly leads to larger values of feedback gains $k_{\mathrm{ND}}, k_{\mathrm{TP}}$ and $k_{\mathrm{TD}}$.

Remark 2. Since positive constants $\gamma$ and $\eta$ can be arbitrarily chosen between 0 and 1 , inequality (22) is easy to be satisfied by choosing $\gamma$ to be close enough to 1 and $\eta$ to be close enough to 0 . However, larger $\gamma$ also leads to larger $k_{\mathrm{TP}}$ and $k_{\mathrm{TD}}$.

\section{Numerical Simulation with Discussions}

\subsection{Description of the Numerical Simulation}

To verify the stabilization capability of PD control (27), it is applied to the power-level regulation of an MHTGR of the HTR-PM plant. Here, the dynamic model of the MHTGR used in this simulation adopts that one composed of both nodal neutron kinetics and nodal reactor thermal-hydraulics given in [20]. The OTSG adopts the moving boundary model presented in [21]. The model of the steam turbine and that of the electrical genera- 
tor are also included in the simulation code [22]. The controller parameters are selected as $k_{\mathrm{NP}}=k_{\mathrm{ND}}=0.5, \gamma=$ 0.5 . Here, $q_{\mathrm{R}}$ is set to be variable.

\subsection{Simulation Results}

In this simulation, the case of large-range power-level maneuver of the MHTGR is studied to show the feasibility of PD power-level control (27). As the power demand signal decreases linearly from $100 \%$ full power-level (FP) to 50\% FP in 5 minutes, the error signals of the nuclear power and the helium temperature cause the powerlevel control to generate proper control rod speed to cope with the decrease of power demand. The responses of relative nuclear power, average fuel temperature and outlet helium temperature as well as the designed rod speed with different values of $q_{\mathrm{R}}$ are all shown in Figure 3.

\subsection{Discussions}

From Figure 3, we can see that the dynamic performance of reactor thermal-hydraulic loop is higher if $q_{\mathrm{R}}$ is larger. Moreover, a larger $q_{\mathrm{R}}$ results in the deterioration of the response of neutron kinetics. Actually, this phenomenon can be interpreted by the proof of Theorem 1 .

From Equation (18), it is clear that the ratio of $V_{\mathrm{T}}$ in $V_{1}$ is higher if $q_{\mathrm{R}}$ is larger. Since $V_{\mathrm{T}}$ denotes the Lyapunov function of the thermal-hydraulic loop, larger ratio of $V_{\mathrm{T}}$ results in faster convergence of those thermal-hydraulic state-variables, which can be easily seen from Figures 3(b) and (c). On the other hand, from Equation (26), larger $q_{\mathrm{R}}$ leads to smaller $\tilde{k}_{\mathrm{ND}}$, which then weaken the convergence of neutron kinetic states. As we can see from Figure 3(a), the oscillation of the relative nuclear power is tougher if $q_{\mathrm{R}}$ is larger. Thus, from the above discussion,
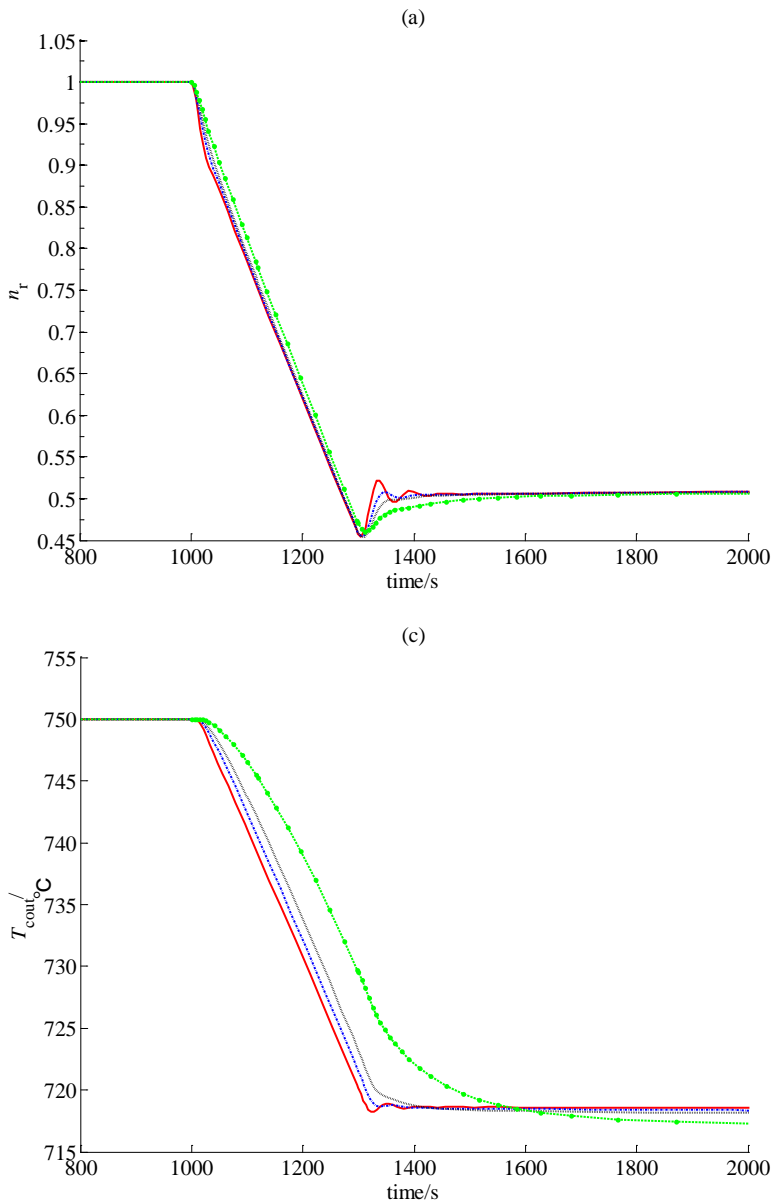

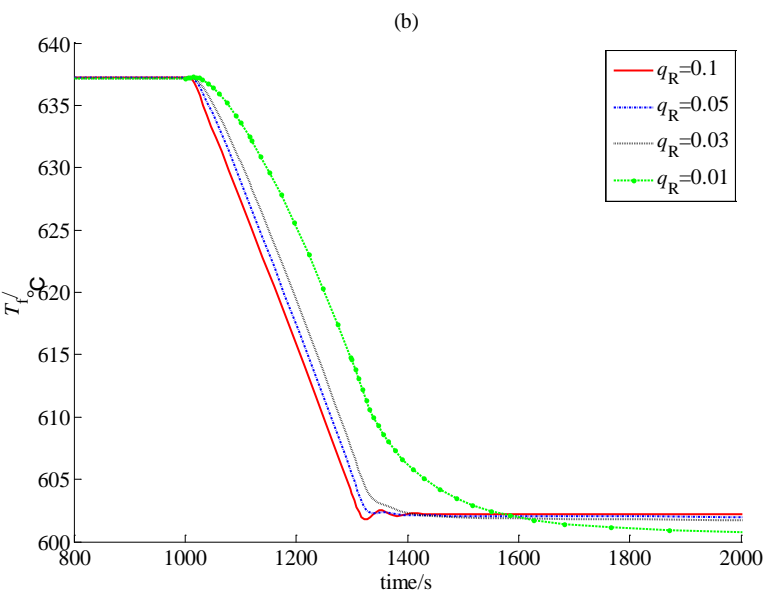

(d)

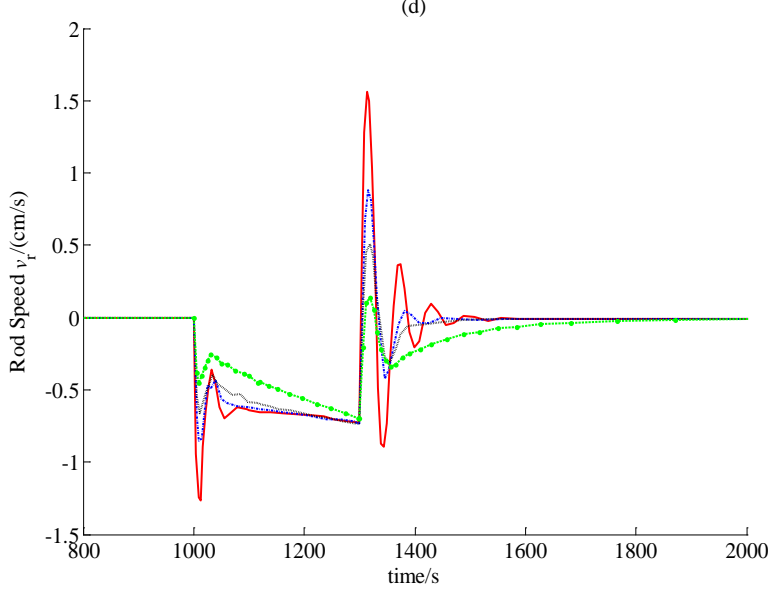

Figure 3. Numerical simulation results: (a) Relative nuclear power, (b) Average fuel temperature, (c) Outlet helium temperature, (d) Designed control rod speed signal. 
we can see that the numerical simulation results given in Section 4.2 are in accordance with the theoretical analysis in Section 3. Moreover, the numerical simulation results also illustrate the relationship between dynamic performance and controller parameters.

\section{Conclusion}

Due to its inherent safety feature and potential economic competitive power, the modular high temperature gascooled reactor (MHTGR) has already been seen as one of the best candidates in building SMR-based nuclear power plant. Since power-level control is meaningful in providing safe, stable and efficient reactor operation, and an MHTGR is essentially a nonlinear dynamic system, it is crucial to develop nonlinear power-level control which can be easily implemented. Based upon the shifted-ectropies of both neutron kinetics and reactor thermal-hydraulics, it is proved theoretically that the simple PD power-level control can provide globally asymptotic closed-loop stability for the MHTGR. Numerical simulation results are consistent with the theoretical analysis, and also showed the relationship between the regulating performance and controller parameters.

\section{Acknowledgements}

The work in this paper is jointly supported by Natural Science Foundation of China (NSFC) (No. 61374045), Tsinghua University Initiative Scientific Research Program (No.20121087992) and National S\&T Major Project (No. ZX06901).

\section{References}

[1] Lohnert, G.H. (1990) Technical Design Features and Essential Safety-Related Properties of the HTR-Module. Nuclear Engineering and Design, 121, 259-275. http://dx.doi.org/10.1016/0029-5493(90)90111-A

[2] Wu, Z., Lin, D. and Zhong, D. (2002) The Design Features of the HTR-10. Nuclear Engineering and Design, 218, 2532. http://dx.doi.org/10.1016/S0029-5493(02)00182-6

[3] Hu, S., Liang, X. and Wei, L. (2006) Commissioning and Operation Experience and Safety Experiment on HTR-10. Proceedings of 3rd International Topical Meeting on High Temperature Reactor Technology, Johanneshurg, D00000052.

[4] Zhang, Z., Wu, Z., Wang, D., Xu, Y., Sun, Y., Li, F. and Dong, Y. (2009) Current Status and Technical Description of Chinese $2 \times 250$ MWth HTR-PM Demonstration Plant. Nuclear Engineering and Design, 239, 2265-2274. http://dx.doi.org/10.1016/j.nucengdes.2009.02.023

[5] Shtessel, Y.B. (1998) Sliding Mode Control of the Space Nuclear Reactor System. IEEE Transactions on Aerospace and Electronic Systems, 34, 579-589. http://dx.doi.org/10.1109/7.670338

[6] Dong, Z. (2011) Nonlinear State-Feedback Dissipation Power Level Control for Nuclear Reactors. IEEE Transactions on Nuclear Science, 58, 241-257. http://dx.doi.org/10.1109/TNS.2010.2091970

[7] Kokotović, P. (1992) The Joy of Feedback. IEEE Control Systems, 12, 7-17. http://dx.doi.org/10.1109/37.165507

[8] Dong, Z., Feng, J., Huang, X. and Zhang, L. (2010) Dissipation-Based High Gain Filter for Monitoring Nuclear Reactors. IEEE Transactions on Nuclear Science, 57, 328-339. http://dx.doi.org/10.1109/TNS.2009.2034743

[9] Dong, Z., Huang, X. and Zhang, L. (2011) Output-Feedback Load-Following Control of Nuclear Reactors Based on a Dissipative High Gain Filter. Nuclear Engineering and Design, 241, 4783-4793. http://dx.doi.org/10.1016/j.nucengdes.2011.02.029

[10] Etchepareborda, A. and Lolich, J. (2007) Research Reactor Power Controller Design Using an Output Feedback Nonlinear Receding Horizon Control Method. Nuclear Engineering and Design, 237, 268-276.

http://dx.doi.org/10.1016/j.nucengdes.2006.04.002

[11] Eliasi, H., Menhaj, M.B. and Davilu, H. (2011) Robust Nonlinear Model Predictive Control for Nuclear Power Plants in Load Following Operations with Bounded Xenon Oscillations. Nuclear Engineering and Design, 241, 533-543. http://dx.doi.org/10.1016/j.nucengdes.2010.12.004

[12] Eliasi, H., Menhaj, M.B. and Davilu, H. (2012) Robust Nonlinear Model Predictive Control for a PWR Nuclear Power Plant. Progress in Nuclear Energy, 54, 177-185. http://dx.doi.org/10.1016/j.pnucene.2011.06.004

[13] Maschke, B.M., Ortega, R. and van der Schaft, A.J. (2000) Energy-Based Lyapunov Functions for Forced Hamiltonian Systems with dissipation. IEEE Transactions on Automatic Control, 45, 1498-1502. http://dx.doi.org/10.1109/9.871758

[14] Ortega, R., van der Schaft, A.J., Maschke, B.M. and Escobar, G. (2002) Interconnection and Damping Assignment 
Passivity-Based Control of Port-Controlled Hamiltonian Systems. Automatica, 38, 585-596. http://dx.doi.org/10.1016/S0005-1098(01)00278-3

[15] Ortega, R., van der Schaft, A.J., Castaños, F. and Astolfi, A. (2008) Control by Interconnection and Standard PassivityBased Control of Port-Hamiltonian Systems. IEEE Transactions on Automatic Control, 53, 2527-2542. http://dx.doi.org/10.1109/TAC.2008.2006930

[16] Dong, Z. (2013) Nonlinear Dynamic Output-Feedback Power-Level Control for PWRs: A Shifted-Ectropy Based Design Approach. Progress in Nuclear Science, 68, 223-234. http://dx.doi.org/10.1016/j.pnucene.2013.07.006

[17] Dong, Z. (2013) PD Power-Level Control Design for PWRs: A Physically-Based Approach. IEEE Transactions on Nuclear Science, 60, 3889-3898. http://dx.doi.org/10.1109/TNS.2013.2277866

[18] Dong, Z. (2012) Dynamic Output Feedback Power-Level Control for the MHTGR Based on Iterative Damping Assignment. Energies, 5, 1782-1815. http://dx.doi.org/10.3390/en5061782

[19] Dong, Z. (2012) Physically-Based Power-Level Control for Modular High Temperature Gas-Cooled Reactors. IEEE Transactions on Nuclear Science, 59, 2531-2548. http://dx.doi.org/10.1109/TNS.2012.2207126

[20] Dong, Z., Huang, X. and Zhang, L. (2010) A Nodal Dynamic Model for Control System Design and Simulation of an MHTGR Core. Nuclear Engineering and Design, 240, 1251-1261. http://dx.doi.org/10.1016/j.nucengdes.2009.12.032

[21] Li, H., Huang, X. and Zhang, L. (2008) A Lumped Parameter Dynamic Model of the Helical Coiled Once-Through Steam Generator with Movable Boundaries. Nuclear Engineering and Design, 238, 1657-1663. http://dx.doi.org/10.1016/j.nucengdes.2008.01.009

[22] Dong, Z. and Huang, X. (2013) Real-Time Simulation Platform for the Design and Verification of the Operation Strategy of the HTR-PM. Proceedings of the 21st International Conference on Nuclear Engineering, Chengdu, 29 July-2 August 2013. 